\title{
LAS VENTAS DE LAS JURISDICCIONES DE TOLERANCIA EN EL XVII. ANALISIS DE UN CASO CONCRETO
}

\author{
por \\ Antonio Herrera Garcia \\ Catedrático del I. B. «San Isidoro» de Sevilla
}

Los años del reinado de Felipe IV constituyen sin ninguna duda una época de considerable aumento de la presión fiscal $y$, aunque en trabajos muy notables se ha tratado de encauzar en sus justas proporciones lo que venía siendo una tópica afirmación (1), el hecho histórico enunciado sigue teniendo plena validez y otros trabajos de investigación posteriores, que no es éste el lugar para reseñar, han venido a corroborarlo de vez en cuando.

A los impuestos establecidos con anterioridad al reinado de este monarca, la Real Hacienda durante ese reinado fue añadiendo otros de nueva creación y buscando recursos en otros ingresos, hinchando el contenido de las aregalías» o facultades y derechos regios, para cuya exacción el monarca no necesitaba del consentimiento de las Cortes. Según A. Domf́nguez Ortiz, de estos nuevos ingresos, creados bajo Felipe IV, que podrian ser calificados de "violentos y extraordinarios", se obtuvieron las cantidades más sustanciosas, y entraron en ellos alteraciones de la moneda, donativos y empréstitos forzosos, ventas de cargos, tierras y jurisdicciones, etc. (2).

(1) Por ejemplo, y a pesar de los años transcurridos desde su publicación, A. Domfnguez OrTIz, Politica y Hacienda de Felipe IV, Madrid, 1960.

(2) Op. cit., pág. 227. 
De uno de estos últimos medios de obtener recursos se tratará aqui, el de las ventas de las llamadas jurisdicciones de permisión o tolerancia. Constituía esta jurisdicción la facultad de elegir y nombrar alcalde y demás cargos de justicia de las villas y lugares del reino, facultad que por tradición y tolerancia real o por expreso traspaso residía o en los vasallos vecinos de tales villas y lugares o en los señores que los poseían. Quizás el nombre que se le aplicó, al suscitarse la cuestión de su venta durante el citado reinado, proviniese de las que desde los siglos anteriores se denominaban alcabalas de tolerancia $y$ de permisión, refiriéndose "a las que estaban en poder de particulares (casi siempre nobles), sin más título que la posesión inmemorial y la tolerancia regia» (3).

En lo tocante a la designación de las justicias concejiles se partía del principio de que el monarca era «cabeza y centro de la justicia», de quien dimanaban por delegación las competencias de todos los oficiales encargados de ella. Pero con las sucesivas donaciones o ventas de señoríos jurisdiccionales y con las concesiones de privilegios forales a los concejos se había producido una dejación de tal principio o permisión en su aplicación práctica y la situación era bastante confusa a tal respecto. Ya CASTILlo DE Bovadilla en el XVI intentaba poner las cosas en su sitio al escribir que

... concedida o vendida por el Rey la villa o el vasallaje, el territorio o el castillo era visto con la universidad concederse y venderse la jurisdicción y dignidad anexa a ello: pero por las leyes de Partida y otra ley real más nueva (quitó muchas dudas) no se comprehenderá en tal concesión o venta jurisdicción alguna, si por palabras expressas y claras no se dixesse o significasse, y con uso y exercicio della por tiempo legítimo no se prescribiesse: y assi, no estando comprehendida ni prescripta la dicha jurisdicción, no la podrán los señores de vasallos exercer en primera ni en segunda instancia, como la puede exercer e introducir el Rey en sus señoríos: y esto es por dos razones: una, porque los más pueblos destos Reynos tienen derecho de elegir Alcaldes ordinarios que conozcan de primera instancia por privilegio o costumbre [...]. La otra razón es porque en el Rey de España reside la jurisdicción de su Reyno y sólo él puede enviar jueces que conozcan de primera instancia con los Alcaldes ordinarios [...]. Pero si en la venta o donación de la villa se dixeren palabras que denoten haber sido voluntad e intención del Rey conceder la jurisdicción della, derecho tendrá en ella el señor, si la usó y exerció (4).

(3) Ibidem, pág. 197.

(4) J. CAStillo DE Bovadilla, Politica para corregidores y señores de vasallos, 
Más cercano a los años de nuestro asunto, en un Discurso sa bre la Real Hacienda, manuscrito de mediados del XviI, escrito anónimamente por alguien que conocía bien el tema, pues en él declara que casi todo el discurso de su vida ha sido empleado en ese ministerio, se decía, expresando lo que debía ser el parecer de los fiscales reales a la sazón y tratando de dar por sentados ciertos extremos, que

Con que es constante no haber sido comprendida en las ventas de va. sallos la jurisdicción de tolerancia, porque donde S.M. la ha vendido a los señores ha sido dándoles facultades para hacer estas elecciones libremente a su voluntad, sin proposición alguna ni dependencia de los vasallos. $\mathrm{Y}$ aunque algunos compradores de vasallos lo han querido interpretar a su favor, no puede tener fundamento cuando con cada uno está capitulado lo contrario y por S.M. declarado y resuelto [en varios casos concretos, como sobre los lugares del estado de Sanlúcar la Mayor y sobre la villa de Aznalcázar] (5).

Apoyada en estos argumentos y acuciada por la necesidad de allegar recursos, la Real Hacienda decidió poner a la venta las jurisdicciones de tolerancia de las villas y lugares en los que no estuviese expresamente traspasada o vendida anteriormente. Por sendas Reales Cédulas de 1634 y 1635 se ordenó que se llevasen a cabo las ventas de tales jurisdicicones, de las que se hallaban usando hasta entonces señores o vasallos en los lugares de señoríos por permisión o tolerancia, y se dieron al mismo tiempo en aquellas Cédulas las instrucciones sobre la forma de realizarlas.

Es posible pensar que la compra de estas jurisdicciones en los lugares que se realizaron debieron ser promovidas, entre otras, por las siguientes circunstancias: en determinados lugares, donde la autoridad del señor no se veía gravemente contestada, pudo ser suscitada por un deseo de aquél con objeto de reforzarla, ya viniese su posesión señorial de antiguo o se hallase recién adquirida, y en tal caso la compra de tal jurisdicción se efectuó por iniciativa señorial y se llevó a efecto con pacífica normalidad; en otros lugares, donde las competencias señoriales eran seria-

Amberes, 1704, 2 vols. (Edición facsímil del Instituto de Estudios de Administración Local, Madrid, 1978), Libro II, Capítulo XVI (Del origen, preeminencias y jurisdicción de los Duques, Condes y Marqueses y de los otros señores de vasallos), núms. 70 a 75. La obra de Bovadilla es de fines del xvi y, por lo tanto, no hace ninguna referencia a las ventas de la tolerancia. Sobre la multiplicidad de casos en que la justicia se encontraba en el XVI en los dominios señoriales y su origen puede verse en A. M. GuILARTE, El régimen señorial en el siglo XVI, Madrid, 1962.

(5) Real Academia de la Historia, Madrid, Colección Salazar, K-80, folios 167-179. 
mente discutidas, el impulso debió venir de considerar la adquisición de esta facultad como un decisivo factor para inclinar la balanza hacia una de las partes y si, en determinados casos, fue una baza conseguida victoriosamente por el señor, en otros, después de diversos conflictos y litigios, los vasallos consiguieron retrotraer para sí la compra de las indicadas jurisdicciones y mantener con ello cierta situación de especiales autonomías concejiles dentro de la estructura señorial.

En el análisis detallado del caso que aquí se expone se podrá comprobar cómo se originó y desarrolló un caso particular y concreto de este tipo de ventas, el de Villanueva del Ariscal, que cae dentro de la segunda y más complicada de las situaciones senaladas.

El señorío de Villanueva del Ariscal, villa situada en el centro de la comarca del Aljarafe sevillano, había sido comprado en la primera mitad del siglo xvi por el Conde de Gelves, para cuya venta Carlos I había desmembrado previamente tal señorío de la Orden de Santiago, a la que hasta entonces había pertenecido dicha villa. Muy pronto, a mediados de ese mismo siglo, el Concejo de Villanueva entabló pleitos con la Condesa de Gelves, doña Isabel Colón, y con su hijo y heredero, don Alvaro de Portugal, sobre la pertenencia de la facultad de nombrar los oficios concejiles de la villa, consiguiendo el Concejo de ésta, mediante una sentencia y carta ejecutoria de 1550 y otras dos de 1559, ver reconocidos por la Chancillería de Granada sus derechos a elegir y nombrar sus propios oficiales, a organizar por sí mismo los juicios de residencias de tales oficiales y a no compartir con los Alcaldes mayores, nombrados por aquellos Condes, la justicia en primera instancia. En la segunda mitad de ese mismo siglo unos chispazos provocados por tales Alcaldes mayores, que trataban de encontrar resquicios por los que viabilizar la injerencia señorial en la administración concejil de la villa, condujeron igualmente a otros fracasos para los representantes de los Condes que ostentaban el señorío de la villa, como ya se ha expuesto en anteriores trabajos (6).

(6) Las cuestiones brevemente reseñadas en este párrafo las he estudiado en mis artículos aLa venta de Villanueva del Ariscal al Conde de Gelves (1537)», pu- 
Parece que tras los últimos conflictos suscitados entre el Concejo de la villa y los Alcaldes mayores, representantes del Conde de Gelves y de sus intereses, ocurridos en 1570, se produjo en estas relaciones entre el señor y sus Alcaldes mayores, por una parte, y los vasallos y su representación concejil, por la otra, si no la paz, al menos cierto apaciguamiento que duró hasta finales del primer tercio del xvir. En esos años, aunque la enemistad Condes-Concejo seguiría latente, si se produjeron algunos roces o altercados, no debieron salir del ámbito local, sin ninguna trascendencia procesal: no hemos hallado documento que demuestre otra cosa, sino sólo la constancia escrita de las notificaciones a los Alcaldes mayores, nombrados por los Condes para Villanueva, de las ejecutorias granadinas ganadas por ésta, y las correspondientes aceptaciones de las mismas por aquellos Alcaldes.

Pero, a finales de la cuarta década de este siglo, ocurrió uno de los sucesos que más resonancia debió tener en todo el Aljarafe, y que daría con seguridad tema de conversación a todos los vecinos de Villanueva durante una buena temporada. Desde 1636 era Duque de Veragua don Pedro Nuño Colón y Portugal, en quien recayó también el Condado de Gelves por herencia, ya que era hijo del IV Duque de aquel título colombino, don Alvaro Jacinto Colón y Portugal, y de su esposa, doña Catalina de Portugal y Castro, V Condesa de Gelves. Persona que se mostrará muy celosa de sus privilegios y de la etiqueta y respeto debidos a sus altus títulos nobiliarios (7), don Pedro Nuño debió hacer una visita por los lugares de su Estado al entrar en posesión de su señorío y, quizás aconsejado por sus lugartenientes y gobernadores, pensaría que el momento más oportuno para ir a Villanueva sería el de los primeros días del año, en los que su Concejo llevaba a cabo las elecciones de los oficiales concejiles para ese mismo año. Alguno de sus consejeros pensaría que la imponente presencia

blicado en Archivo Hispalense, y aLos pleitos de doña Isabel Colón y sus suce. sores con el concejo de Villanueva del Ariscal», en Hidalguía (Madrid), XXXIII (1985), págs. 225-254 y 749-775.

(7) Se cuenta cómo en una reyerta de sus criados con otros, en Madrid, el Duque llevó muy a mal, al intervenir en la misma, que los criados que atacaban a los suyos no se descubriesen ante su persona, provocando al castigarlos por tamaña insolencia un conflicto con la justicia real, que le valió un corto destierro en Santorcaz ("Cartas de algunos PP. de la Compañía de Jesús...», en el Memorial Histórico Español, vol. XVIII, págs. 22-27). Posteriormente, en Nápoles, en 1656, tuvo también sus diferencias con motivo del tratamiento que se le debía dispensar (R. MAGdaleno ReDOnDo, Papeles de Estado de la correspondencia y negociación de Nápoles, Valladolid, 1942, leg. 3279). 
del señor bastaría para meter el resuello en el cuerpo a los electores del Concejo de Villanueva.

Gracias a una información de testigos, realizada años después por el Concejo de Villanueva, podemos reconstruir lo que ocurrió en esta ocasión. En aquella información uno de los testigos, el vecino de la villa Francisco Limón el Viejo, de setenta años de edad, declaraba que, hacia 1638, haría unos cuarenta años poco más o menos, que, siendo Alcaldes ordinarios en esta villa Juan de Pineda el Viejo y Juan de Pineda el Rojo, vio... que el Duque de Veragua, que entonces era abuelo del que hoy es (8), vino a esta villa por este tiempo (9) a ver hacer las elecciones, que en ella se hacian, de Alcaldes ordinarios y demás oficiales. En presencia de este testigo el dicho Duque de Veragua les dijo a los dichos Alcaldes que entrasen a hacer sus elecciones en quien ellos quisiesen, que él no quería nombrar a nadie, sino tan solamente aprobarlos y firmarlos. A que respondió el dicho Alcalde Juan de Pineda que Su Excelencia no mandase tal cosa, porque él ni su compañero no lo habian de consentir, que si lo consintieran los niños los habian de apedrear, y esto mirando al bien común de la república y a la posesión en que estaban... Con que el dicho Duque de Veragua se fue y los dejó (10).

Ante lo que el Duque de Veragua, Grande de España que podía cubrirse ante el Rey, hubo de considerar a buen seguro como una insolencia intolerable hacia su persona y rango, debió él mismo disponer inmediatamente que se encontrasen los medios para cas-

(8) El Duque abuelo que cita, don Pedro Nuño Colón y Portugal, tenía exactamente los mismos nombres y apellidos que su nieto, que es el que posee el título en 1678 cuando se está efectuando esa información. El primero, protagonista del suceso que ahora se cuenta, debía ser muy joven al tiempo de este lance, pues debía contar unos catorce años.

(9) Principios de ese año 1638.

(10) A.A.T.S., leg. Hco. 266; las declaraciones de este testigo en los folios 532536 , y, lo transcrito, en la respuesta a la pregunta $7 .^{\circ}$ Otros testigos de la misma información amplían detalles sobre este suceso: Juan Rodríguez Correa, de más de sesenta años, afirmó que por la referida actitud, mantenida por Juan de Pineda ante el Duque, éste lo tuvo preso en Gelves, soltándole a ruegos de la Duquesa (declaraciones en los fols. 550-554, respuesta a la pregunta 7). Sebastián de la Oliva, de setenta y cuatro años, precisó que el Duque le quebró la vara de justicia a Juan de Pineda y le tuvo preso más de un año, a pesar de lo cual no se salió con su intento (declaraciones en los fols. 556-559, respuesta a la pregunta 2). Y Diego Marín, de setenta y cinco años, contó cómo todos los capitulares se salieron del cabildo, para no llevar a cabo la elección con el Duque, y cómo, habiendo llamado éste dos o tres veces por su nombre a Juan de Pineda, no le contestó hasta que le llamó «Alcalde Juan de Pineda»; le dijo entonces el Duque que reuniese el cabildo que él no entraría, y así se hizo en efecto (declaraciones en los fols. 575-578, respuesta a la pregunta 4). 
tigar tal impertinencia y de evitar en lo sucesivo que aquella afrenta pudiera repetirse. Claramente vería $\longrightarrow$ le harían ver- que para ello lo que necesitaba era la posesión legal de la facultad de nombrar a los oficiales del Concejo, o al menos de confirmar las elecciones que aquel Concejo hiciese, y la de someterlos a juicio de residencia, una vez terminado el período de su actuación en el cargo. Esto era precisamente lo que había estado varias veces en litigio desde hacía ya casi un siglo, sin que los Condes lo hubiesen conseguido, por lo que, para un deseo de satisfacción lo más inmediata posible, seguir un nuevo pleito no era camino aconsejable. Entonces, guiado posiblemente por sus asesores, intentó una nueva vía, por la que este asunto se conectó con la cuestión general expresada al principio.

Si el Concejo de Villanueva del Ariscal pretendía poseer tales derechos, que en resumen constituían en su conjunto lo que entonces se llamaba jurisdicción de tolerancia, y esos derechos no habían pasado a ser propiedad señorial con la venta de la villa al Conde de Gelves, en tal caso la posesión eminente de los mismos seguía perteneciendo a la Corona: el Duque de Veragua pidió al Rey que le hiciese la gracia de concederle esa jurisdicción como uno de los medios para compensarle los diez mil ducados de servicio, qui l. ofrecía al Monarca a cambio de la leva de vasallos, que el Duqui ' in tenía en Castilla. En otras palabras: le proponía la compra de 1 , jurisdicción de tolerancia de Villanueva: Precisamente por enlinces hacía muy poco tiempo que, como vimos al comienzo, se hilbían promulgado y difundido las Cédulas Reales que autorizaban la enajenación de tales jurisdicciones.

Aceptado el ofrecimiento del Duque, por una Real Cédula de 5 de octubre de 1639 (11), dirigida a don Antonio Sánchez de Taybo, contador del Rey en Sevilla, tras de exponer la petición del Duque y declarar que se accedía a lo que el mismo había solicitado, se le ordenó al mentado contador ir "con vara alta de justicia" a Villanueva, averiguar los vecinos y moradores que

(11) Archivo General de Simancas (AGS), Mercedes y privilegios, leg. 353, f. 4. Existe transcripción de esta Cédula en el Archivo de la Audiencia Territorial de Sevilla (AATS), leg. cit., fols. 45-51. Parece oportuno recordar aquí sobre las necesidades de la Real Hacienda en estas fechas que en 1635, al abrirse el último período de la Guerra de los Treinta Años, se declaró oficialmente la guerra entre Francia y España; en 1637, las operaciones militares en los Pirineos, a las que se unieron levantamientos populares en Portugal (Evora) y la inquietud en Cataluña, no hicieron más que aumentar constantemente las necesidades económicas y militares del gobierno del Conde Duque de Olivares. 
tenía la villa y su término, recoger los padrones de ello $\mathrm{y}$, una vez comprobados si estaban en regla, enviar toda la información al Consejo de Hacienda para que éste ajustase lo que, según la vecindad que la villa tuviese, valiese la solicitada jurisdicción.

Si no lo sabía ya por otros conductos, la investigación encargada al Contador real hizo conocer al Concejo de Villanueva el intento del Duque e inmediatamente lo contradijo por vía judicial. A pesar de ello el Consejo de Hacienda ordenó que corriese la venta de la tolerancia; entonces la villa envió a Madrid a un Procurador y pidió el retracto de dicha venta por el tanto en que se había efectuado: le amparaba el derecho reconocido por Reales Cédulas, que posibiiltaba el tanteo y retroventa a los propios lugares cuyas jurisdicicones de permisión y tolerancia se hubiesen vendido a los señores de los mismos, aunque una Real Cédula de junio de 1638 había limitado este derecho a los cuarenta días inmediatos posteriores a la notificación de dicha venta. Aceptado el derecho de opción a la compra que asistía a Villanueva en esta cuestión, se efectuó la retroventa a la villa de la citada jurisdicción, expidiéndose ejecutoria de ello en Madrid, a 29 de noviembre de 1656, previo pago pujado a la Real Hacienda de 657.500 maravedís (núm. 1 del Apéndice documental), importe de los 263 vecinos de la villa, estimados a razón de 2.500 maravedís cada uno.

Como ésta era una cantidad que, ni por asomo, el Concejo de Villanueva poseía en sus arcas, para liquidarla hubo que hacer un reparto del gasto entre unos vecinos y acudir a la voluntaria generosidad de otros, ya que por una serie de concausas, entre las que figuraban la penuria financiera de la Monarquía, la política de prestigio del Conde Duque de Olivares, la defensa de vetustos derechos señoriales y el deseo de autonomía administrativa de la propia Villanueva, ésta se veía obligada a comprar la propiedad de unas prerrogativas, que de hecho disfrutaba desde hacía siglos y que incluso tenía reconocidas de derecho por las aludidas sentencias judiciales del siglo XvI.

La Provisión Real, en la que se ordenó dar posesión de esta facultad nuevamente adquirida por la villa, lleva fecha de 7 de diciembre de 1656 (núm. 2 del Apéndice documental), y la toma efectiva de esta posesión se realizó en las Casas de Cabildo de la propia Villanueva el día de Nochebuena de ese mismo año, dándosela Diego Alonso Recocho, Alcalde ordinario de la vecina villa de Salteras, que había sido requerido legalmente para ello: éste, 
ante el escribano de la villa Pedro Luis de la Parra, apuso al Concejo de la misma en posesión de la jurisdicción de tolerancia de dos Alcaldes ordinarios, dos regidores, dos alguaciles ordinarios y trece capitulares, sin mitad de oficios y todos con voz y voto en el Cabildo, y así mismo dos alcaldes de la Hermandad y un mayordomo de Concejo sin voz ni voto». Los caudales del pueblo habían disminuido, pero aquella Navidad pudo ser celebrada en Villanueva con un nuevo triunfo sobre los señores de la villa (12).

Por estos mismos años y probablemente en relación con esta misma cuestión, se había producido en la villa un nuevo incidente con otro Alcalde mayor. Andrés de Pujadas, vecino de Sevilla, que es el justicia a quien nos referimos, fue nombrado "Alcalde mayor del Condado de Gelves y, especialmente, de la villa de Villanueva del Ariscal» en 8 de junio de 1655, y su nombramiento fue expedido por don Agustín Homodei y Portugal, Marqués de Almonacid y Conde de Pavía, del Consejo Real de Hacienda, en nombre de su sobrino el Duque de Veragua, el mentado don Pedro Nuño I, Conde de Gelves (13).

Hagamos aquí un inciso en el relato de este pleito y sus incidentes, ya que en esta familia Homodei recayó precisamente el marquesado de Villanueva del Ariscal en el breve tiempo de la existencia de este título, y nos parece oportuno y pertinente recoger y ordenar aquí, aunque sea de forma resumida, las noticias halladas sobre el mismo, ya que mediante su creación se mantuvo durante algunos años el propósito de separar el señorío de Villanueva de la Casa condal de Gelves, en el origen de cuya decisión posiblemente intervinieron los molestos contratiempos que les ocurrían a los condes con el gobierno de esta villa.

El título de Marquesa de Villanueva del Ariscal fue concedido a doña Leonor de Portugal, hermana del Duque de Veragua y dama de la Reina, en 1629 (14); al concedérsele, como no poseía lugar

(12) A.A.T.S., leg. cit., fol. 230. Del contenido de los capitulares puede ser expresión lo que declaraba un testigo años después: Un vecino, que fue a Madrid el año de 55, a traer despachos para la tolerancia, luego que llegó a Villanueva, salió electo por Alcalde, y se dijo públicamente que salió en premio del viaje que habia hecho y despachos que habia traido (ibidem, fols. $410-414$, respuesta a la pregunta 3).

(13) Este nombramiento se conserva en el AATS, leg. cit., fol. 21 v.

(14) J. BERNI Y CATALA, Creación, antigüedad y privilegios de los Títulos de Castilla, Valencia, 1769, pág. 307; dice erróneamente Arenal, en vez de Ariscal (ver A. Ramos, Aparato para la corrección y adición de la obra que publicó D. Joseph Berni y Catalá, Málaga, 1777, pág. 91). 
ni vasallos en que situarlo, se pensó en que don Alvaro Jacinto, Duque de Veragua, consintiese en la desmembración de Villanueva del mayorazgo de Gelves para proporcionarle con ella la correspondiente base económica a su título; en los términos de la concesión del marquesado se determinaba que el poseedor del título quedaba obligado a pagar anualmente 122.400 maravedís de soldadas desde 1630. La primera y única Marquesa de Villanueva del Ariscal, la citada doña Leonor de Portugal, casó con el también mentado Marqués don Agustín Homodei, milanés, del que no tuvo descendencia. Sin embargo, la proyectada desmembración del señorío de Villanueva de los bienes vinculados al mayorazgo del Condado de Gelves no llegó a efectuarse, en parte porque la propia doña Leonor murió hacia 1637 y, al no dejar hijos legítimos, se extinguió en ella el título en cuestión, pues no había "herederos de sangre» para suceder en él.

Casado don Agustín en segundas nupcias, el hijo mayor de este matrimonio, don Carlos Homodei y Pacheco, pidió en 1657 que no se le expidiese carta de sucesión en el título de Marqués de Villanueva del Ariscal, ya que no le correspondía por habérsele concedido a la primera mujer de su padre, de la que éste no tuvo hijos (15), y la madre del mismo don Carlos, doña María Pacheco solicitó, en 1663, que este marquesado se le trocase a su hijo por el de Almonacid - solicitud que le fue concedida- por pertenecer Villanueva al Duque de Veragua (16). Después de esto no hemos visto citado el título de este efímero marquesado de Villanueva, por lo que es de suponer que quedase desde entonces extinguido.

Volviendo a la cuestión del Alcalde mayor Andrés de Pujadas, gobernador y contador del Estado de Gelves, el Concejo de Villanueva se negó a recibirle como Alcalde mayor, pretextando que el Conde de Gelves no había exhibido privilegio en que demostrase tener facultad suficiente para nombrarle. Evidentemente esta

(15) Catálogo alfabético de los documentos referentes a titulos del Reino y Grandezas de España, conservados en la sección de Consejos suprimidos del Archivo Histórico Nacional, leg. 4.435, núm. 80.

(16) Ibidem, lib. 2.755, núm. 41, fol. 335 v. La Contaduría de Presidios reclamaba, en enero de 1662, a doña María Pacheco, viuda de don Agustín Homodei, 3.549.600 maravedís por lo que en concepto de soldadas debía el título de Marqués de Villanueva del Ariscal, desde 1630 ( «La Real Hacienda con el Estado del Marqués de Villanueva del Ariscal, sobre la paga del servicio de lanzas». AGS, Dirección General del Tesoro, Inv. 24, leg. 864, f. 3). En 1669 quedó este pleito en suspenso, pues no se pudo probar que se hubiesen efectuado la aludida desmembración de Villanueva, ni su inclusión en los bienes del casi nonato título. 
negativa, si no fue una argucia para ganar tiempo, teniendo en cuenta que, simultáneamente, como hemos visto, el propio Concejo intentaba en el Consejo de Hacienda la compra de la jurisdicción de tolerancia de la villa, fue entonces un desliz de los capitulares; al Conde, que no tuvo inconveniente en declarar que dicha negativa se debía a que los componentes del mismo Concejo no querian tener quien le vaya a la mano en las extorsiones que hace (17), le bastó presentar como prueba de que poseía la aludida facultad la carta de venta de la villa «en pergamino, con sello de plomo pendiente y firmada de Carlos I». La Audiencia de Sevilla a su vista, en septiembre de ese mismo 1655, revocó el acuerdo del Concejo, que negó el reconocimiento a Pujadas, y ordenó que le recibiese como tal Alcalde mayor.

Obedeció el Concejo el mandato de la Audiencia (18), aunque uno de los Alcaldes ordinarios de la villa no dejó de notificar inmediatamente al recibido los privilegios ganados por la villa en Granada, que a su vez eran limitaciones a la jurisdicción de aquel justicia, delegado del Conde. Por otra parte, el mayordomo del Concejo, Martín Pérez, procedió a realizar una información de testigos en octubre del mismo año (19), para que quedaran claramente probadas la continuidad y tradición con que tales privilegios se presentaban en la villa; que los anteriores Alcaldes mayores habían residido en Sevilla o en Gelves, pero no en Villanueva (20), y que tales alcaldes sólo habían conocido las causas en grado de apelación, presentando al mismo tiempo un requerimiento en forma a Pujadas en este sentido. Ente tanto un auto de uno de los Alcaldes ordinarios prohibía al escribano público Diego de Castro Verde, de su parcialidad y criado de S. E. secretamente (21), que actuase con el Alcalde Pujadas en causas de primera instancia.

Los capitulares de la villa posiblemente procuraron hacerle insoportable la estancia en ella al Alcalde mayor; por ejemplo,

(17) AATS, leg. cit., fol. 29.

(18) Aparece una certificación de este recibimiento, en 29 de noviembre de 1655 , expedida por el escribano del cabildo Pedro Luis de la Parra, con las reservas del caso, en el AATS, leg. cit., fols. 56-58.

(19) Los testigos fueron Alonso Esteban Artero, Diego de Pineda y Pedro Martín Hidalgo, quienes con diversos cargos habían sido capitulares varios años (Ibídem, folios 52-56).

(20) En la citada carta ejecutoria de 1550 se dice concretamente que los Alcaldes mayores sólo debian venir a la villa cada cuatro meses y, en otro lugar, que solamente permanecerían en ella «de sol a sol».

(21) AATS, leg. cit., fol. 59. 
en cierta ocasión, en la que éste trató de sentarse en la iglesia con el Cabildo, sus componentes no se lo permitieron, no volviendo aquél a intentarlo más (22). Ante tales actitudes y desaires parece que Andrés de Pujadas abandonó Villanueva y no volvió nunca más a ella.

Los conflictos entre los Condes de Gelves y el Concejo de Villanueva se reprodujeron más tarde, pero de ello trataremos más adelante. Por ahora, volviendo a la cuestión de las jurisdicciones de tolerancia y de su venta, hemos sacado la impresión, a través de la documentación consultada para este breve trabajo, que no fueron muchos los señores que la adquirieron: los que gozaban pacíficamente de la facultad de estos nombramientos o los que no les importaba gran cosa que esa prerrogativa estuviese en manos de los vasallos de sus lugares, no debieron preocuparse en absoluto por esta cuestión y no llevaron a cabo ningún tipo de compra.

Cuando el anónimo autor del Discurso señalado al principio, que trataba de proponer determinados medios desde un punto de vista bastante realista - declaraba que «en su vida había sido arbitrista»- para sanear la Hacienda, hablando de este recurso decía que muchos nuevos señores debían pensar que entre sus prerrogativas ya se hallaba la de las elecciones y nombramientos de tales oficiales de justicia,

y esto persuade la evidencia de que han sido muy raros los que han acudido a comprar la tolerancia que siendo, como ha sido, de los demás señores antiguos de vasallos, para ser más dueños dellos y del entero señorío, ya se be que, concurriendo en los modernos la misma razón

(22) Este pintoresco incidente puede reconstruirse casi de verbo ad verbum, siguiendo las declaraciones de los testigos de una probanza, realizada años después (Ibidem, fols. 526-578). Pujadas entró en la iglesia cuando se estaba celebrando una misa, a la que asistía el cabildo municipal corporativamente, presidido por el Alcalde ordinario Leonel de Lara, y pretendió sentarse con los componentes de aquél; pero éstos, para impedírselo, permanecieron de rodillas - para no sentarse con el Alcalde mayor- durante toda la misa y, en cuanto acabó ésta se fueron, sin esperar, como era costumbre, a que saliese el preste sin revestir para darles los buenos días, dejando solo a Pujadas. Al poco tiempo el citado Alcalde Leonel de Lara fue a Sevilla a pagar unos diezmos al Duque y tuvo que ver lógicamente a su contador, Andrés de Pujadas, y se refiere que éste, quejándosele, le dijo - iAh, señor Alcalde! ¿Cómo vuesa merced no me quiso dar mi asiento?, a lo que el señor Alcalde le contestó, - ¿Por qué se lo había de dar, no siendo suyo y estando la villa en posesión? (fol. 550). No había quién los apease. 
y conveniencia, el no haber acudido a solicitarla abrá sido por falta de noticia de los vasallos de haberles quedado reservada esta jurisdicción por tolerancia de S. Magd.,

parece corroborar nuestra impresión. Debido a ello el mismo autor aconsejaba que, ante la confusión existente en los lugares de señorío, se averiguase a quién pertenecía legalmente la facultad en cuestión y, si no la tenían los señores, se restituyese al Rey, vendiéndola luego la Real Hacienda en la forma que estaba mandada a los mismos dueños de dichos lugares o a sus vecinos, si no se hallaban ya en la costumbre de nombrarlos.

Concretamente hemos podido constatar que el Conde Duque de Olivares -quizás para dar ejemplo- adquirió la tolerancia de los lugares de su señorío aljarafeño, así como que también se había comprado la tolerancia de algunos otros lugares, como $\mathrm{Pa}$ terna del Campo y algunos más, pero siempre en una escasa proporción.

De todas formas es necesario insistir en que este parecer es sólo una impresión obtenida a través de una corta cantidad de documentos consultados. Para una evaluación precisa de este hecho habría lógicamente que realizar un estudio mucho más amplio, que desborda desde luego el objetivo que, como se señaló al comienzo, se proponía este corto estudio de un caso concreto.

\section{APENDICE DOCUMENTAL}

Madrid, 17 de noviembre de 1656

Carta de pago, otorgada por el tesorero del Real Consejo de Hacienda a favor del Concejo de Villanueva del Ariscal, mediante la cual acredita haber recibido el importe de la adquisición de la jurisdicción y tolerancia por parte de la dicha villa.

Recibí yo, Antonio Báez de Guzmán, Secretario general y perpetuo del Real Consejo de Hacienda, en el arca de dos llaves con intervención del señor Nicholás de Grixalba, contador de mercedes de S.M., que tiene la una de ellas, de la villa de Villanueva del 
Ariscal por mano de Rodrigo Díaz, seiscientos y cincuenta y siete mil y quinientos mrs. de ellos en plata y los quatrozentos y noventa y tres mil ciento y veinte y cinco mrs. restantes en vellón, que dijo entregarlos por la jurisdicción y tolerancia de la dicha villa, que es lo que importaron los doscientos y sesenta y tres vecinos a dos mil y quinientos mrs. cada uno, cuarta parte en plata. Y la dicha cantidad entregó el dicho Rodrigo Díaz, vecino de la misma villa, en virtud de auto de los señores de dicho Consejo de oy, día de la fecha, y quedan hechos buenos en la quenta aparte de diferentes efectos que se benefician por el dicho Consejo, de que doy esta carta de pago con la dicha intervención.

Fecha en Madrid a diez y siete días del mes de noviembre de mil seiscientos cinquenta y seis años = Antonio Báez de Guzmán $=$ Con mi intervención, Nicholás de Grixalba $=$.

(ARCHIVO MUNICIPAL DE SEVILLA, sec. 5.", tomo 249, expediente 58. Traslado autorizado de 1740.)

Madrid, 7 de diciembre de 1656

Provisión Real de Felipe IV para que por la justicia realenga más cercana se dé posesión de la jurisdicción de tolerancia a la villa de Villanueva del Ariscal.

Don Felipe, por la gracia de Dios Rey de Castilla, de León, de Aragón, de las Dos Sicilias, de Jerusalén, de Portugal, de Navarra, de Granada, de Toledo, de Valencia, de Galicia, de Mallorca, de Sevilla, de Cerdeña, de Córdoba, de Córcega, de Murcia, de Jaén, etc., a vos la nuestra justicia ordinaria realenga más cercana a la villa de Villanueva del Ariscal: Sabed que por parte del concejo, justicia y regimiento de la dicha villa se nos ha hecho relación que la dicha su parte había seguido pleito con el Duque de Veraguas, sobre la jurisdicción de tolerancia de ella, de que se le había despachado nuestra carta ejecutoria por haber pagado el precio que había montado; $y$, atento a que en virtud del título le tocaba a la dicha villa del Ariscal tomar la posesión de la dicha jurisdicción, nos pedía y suplicaba le mandásemos despachar nuestra carta y provisión para que, en conformidad de la 
dicha carta ejecutoria, cualquier Alcalde del dicho Concejo o del realengo más cercano a la dicha villa le diese la dicha posesión, o como fuese nuestra merced. Lo cual, visto por el presidente y oidores de nuestro Consejo y Contaduría Mayor de Hacienda, fue acordado que se diese esta nuestra carta para vos, y Nos tuvimoslo por bien. Por la cual os mandamos que, siendo con ella requerido por parte de dicha villa de Villanueva del Ariscal, vais y os portais a ella con vara alta de nuestra justicia, y por ante un nuestro escribano, que tenga título de nuestros reinos, le daréis la posesión de la jurisdicción de tolerancia, lo cual ejecutaréis en virtud de la dicha nuestra carta ejecutoria, que originalmente para el dicho efecto consta os será mostrada, la cual guardad y ejecutad en todo y por todo según y como en ella se contiene y declara, y contra su tenor y forma no vais, ni paséis, ni consintáis ir ni pasar en manera alguna. $Y$, de conformidad de ella, le daréis y pondréis en la posesión de la dicha jurisdicción de tolerancia, que para ello os damos poder y comisión en forma tan bastante como de derecho se requiere y sea necesario, y no hagáis cosa en contrario, pena de la nuestra merced y de cincuenta mil maravedises para la nuestra Cámara, so la cual mandamos a cualquier escribano os la notifique y de ella dé testimonio. Dada en Madrid a siete días del mes de diciembre de mil y seiscientos y cincuenta y seis años. Licenciado D. Juan de Carvajal y Sande.-Licenciado D. Adrián de Cerda y Arcena.-Licenciado D. Antonio de Monsalve. Dr. D. Francisco Salgado de Somoza. Yo, D. Lucas Francisco de Castañeda, Secretario de Cámara del Rey nuestro señor, la hice escribir por su mandado, con acuerdo de presidente y oidores de su Consejo y Contaduría mayor de Hacienda.-Regidor, D. Pedro de Castañeda.Canciller mayor, D. Pedro de Castañeda.

(ARCH. DE LA AUDIENCIA TERR. DE SEVILLA, leg. His. número 266, fols. 68-69. Traslado aut. ${ }^{\circ}$ de 1677, sacado del original que a la sazón se guardaba en el Concejo de Villanueva.) 
REAL-1987, núm. 235-236. HERRERA GARCIA, ANTONIO. LAS VENTAS DE LAS JURISDICCION...

REAL-1987, núm. 235-236. HERRERA GARCIA, ANTONIO. LAS VENTAS DE LAS JURISDICCION... 


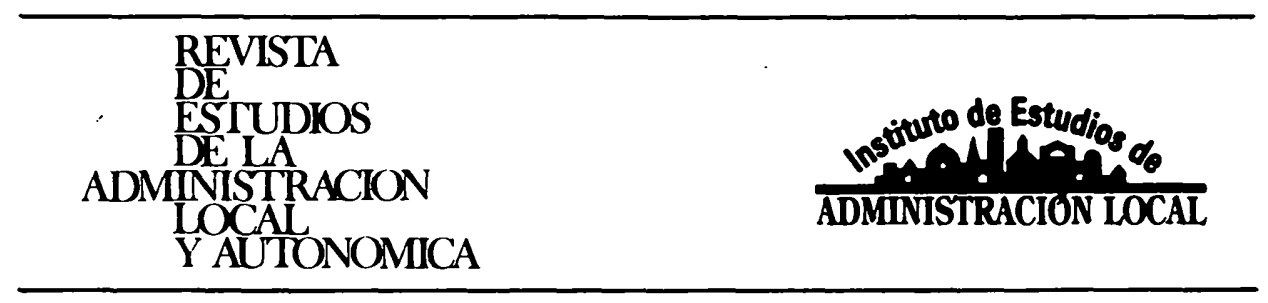

\section{JURISPRUDENCIA}


REAL-1987, núm. 235-236. HERRERA GARCIA, ANTONIO. LAS VENTAS DE LAS JURISDICCION...

REAL-1987, núm. 235-236. HERRERA GARCIA, ANTONIO. LAS VENTAS DE LAS JURISDICCION... 